\title{
NA FRONTEIRA DISTANTE: UM ENSAIO SOBRE A QUESTÃO AGRÁRIA ACRIANA À LUZ DE SUA FORMAÇÃO ECONÔMICA E SOCIAL ${ }^{1}$
}

\author{
CLEILTON SAMPAIO DE FARIAS \\ Instituto de Educação, Ciência e Tecnologia do Acre \\ SILVIO SIMIONE DA SILVA \\ Universidade Federal do Acre
}

\section{Introdução}

Estudos recentes ${ }^{2}$ permitem indicar que, ainda nas décadas de 1970 e 1980, a ocupação de áreas de fronteiras econômicas se constituiu numa das principais formas de avanço do capitalismo no campo e, por consequência, produtora de elementos da dinâmica da questão agrária brasileira. Não por acaso, o Acre nasceu da dinâmica da fronteira econômica do século XIX, tendo suas terras rearticuladas no plano político a partir da fixação de limites internacionais do Brasil com a Bolívia e com o Peru. No entanto, foi somente em meados do século XX, diante da rearticulação do capital na fronteira econômica, com a inserção da agropecuária, que se consolidaram a economia e a sociedade acriana.

${ }^{1}$ Artigo elaborado a partir da dissertação de mestrado "A agroindústria Álcool Verde e a questão agrária no município de Capixaba/AC", defendida no Programa de Mestrado em Desenvolvimento Regional da UFAC, com a orientação do Prof. Dr. Silvio Simione da Silva.

${ }^{2}$ Referimos entre outros a: SILVA [Ferreira da], 1982; SILVA [Graziano da], 1990; SILVA [Simione da], 2003; MARTINS, 1975, 1997; GONÇALVES, 2001; PAULA, 2005 . 
Tal característica é, ainda hoje, condição fundamental, pois quase todo o território acriano está na faixa de fronteira política, ao passo que o processo de produção do espaço estadual é marcado, quase sempre, pelas novas possibilidades de articulação econômica de uso do território. Isso mostra o quanto a condição de ser/estar fronteira econômica ainda está presente no cotidiano da realidade vivida. Situações estas que, em grande parte, são compartilhadas pelos vizinhos territórios bolivianos e peruanos.

Nesse sentido, a condição de estar na fronteira, fixar bases onde se separa de seus vizinhos, num plano externo, mas se une em outro plano interno, é a base da formação territorial e a origem dos problemas agrários. Assim, compreender as dinâmicas ocasionadas destas frentes, como componentes formadoras da fronteira, é um caminho para entender o avanço do capitalismo e dos conflitos e problemas gerados na Amazônia Acriana.

Sendo assim, busca-se situar o Acre no contexto da questão agrária brasileira, através da análise da dinâmica da fronteira, suas fases e marcas espaciais deixadas no agrário regional, expressas na estrutura fundiária concentrada. Numa relação dialética (vista no movimento do processo histórico de formação socioterritorial), procura-se, também, pontuar o que caracterizou a questão agrária acriana no longo processo de sua formação econômica/social. Para tanto, desenvolve-se na primeira parte do texto uma análise sobre conceitos e concepções de frente/fronteira relacionadas com o movimento de articulação do capital em nível nacional e seus desdobramentos no espaço acriano. Na segunda parte, apresentam-se as implicações das frentes/fronteiras na questão agrária local com a análise da estrutura fundiária.

\section{Fronteiras interpretativas da fronteira}

Para nós, geógrafos, a discussão acerca dos significados, aplicações e representações do termo "fronteira" é muito ampla e importante. Há muito tempo, o termo já era usado numa concepção política, para se referir ao espaço proveniente da divisão entre países. Mais recente, passou a ser usado para expressar uma dinâmica populacional com forte influência nos valores demográficos e, também, referido como o lugar proveniente de mudanças socioespaciais de caráter econômico. 
O historiador norte-americano Frederick Jackson Turner afirmou que o significado da fronteira na história americana, ou seja, o "Oeste" passa por uma evolução social, amálgama de raças, miscigenação. No caso americano, a fronteira proporcionou o crescimento do nacionalismo, a evolução das instituições políticas e o seu principal legado foi a formação da democracia americana (KNAUSS, 2004).

O estudo de Turner sobre o "Oeste" americano foi uma das principais obras teóricas que exprimiu a fronteira como fenômeno importante para a formação de uma nação, desde o desenvolvimento da população, da conquista do território e da formação de um governo soberano. De certa forma, houve forte influência desse estudo nos teóricos brasileiros como Gilberto Freire (1947), Sérgio Buarque de Holanda (1945, 1957, 1973) e Cassiano Ricardo (1970). Todos eles fizeram interpretações similares à de Turner na formação social e territorial do Brasil.

No entanto, na eminente política do governo de Vargas de efetivar no território brasileiro um movimento intitulado "marcha para oeste", como uma tentativa de forjar uma dinâmica similar aos acontecimentos da fronteira americana, coube ao geógrafo Leo H. Waibel (1955) a diferenciação de significados entre o termo pioneiro, fronteira e zona pioneira.

A expressão "pioneiro" é originária da terminologia militar e significa "escoteiro", "batedor". Nos Estados Unidos, entretanto, esta palavra foi empregada num sentido econômico, referindo-se ao homem que é o primeiro a penetrar na mata, ajudando a torná-la acessível à civilização e que, por isso, promove o deslocamento da "frontier" sertão adentro. [...] $\mathrm{Na}$ Europa, a palavra "frontier" significa o limite político que separa dois países vizinhos. Nos Estados Unidos, o termo recebeu, além disso, um sentido econômico: "passou a significar o limite da zona povoada". E enquanto a fronteira como limite político representa uma linha nitidamente demarcada, a fronteira no sentido econômico é uma zona, mais ou menos larga, que se intercala entre a mata virgem e a região civilizada. A esta zona damos o nome de zona pioneira (WAIBEL, 1955, p. 04).

Conforme Waibel (1955, p. 05) haveria duas áreas para se distinguir: a fronteira demográfica, que é o avanço populacional sobre a mata virgem com a formação de uma nova zona povoada e que por isso, também é conhecida por zona pioneira e a fronteira econômica, que é a zona onde as atividades econômicas e a sociedade já se encontram consolidada. Ou seja, 
a primeira (fronteira demográfica) limita o sertão com a mata virgem para oeste, já a segunda (fronteira econômica) separa o sertão a leste da região economicamente mais adiantada.

Diferente de Waibel (1955), Martins (1982, p. 75) não concordou que a área de expansão seja chamada de zona pioneira. Na verdade, já não é mais pioneira porque esse movimento intitulado de "civilizador" é posterior ao indígena. Para ele, as "zonas" referidas por Waibel são na verdade "frentes", então, a dinâmica "civilizadora" de expansão demográfica sertão a dentro ocasionada por pequenos agricultores e posseiros, pode ser chamada de "frente de expansão". A "frente pioneira" ocorre posterior à expansão e é pioneira nas formas sociais e econômicas de exploração e dominação vinculadas ao capitalismo.

Segundo Martins (1982) após a frente de expansão, um segundo movimento é constituído pela forma empresarial e capitalista de ocupação do território - é a grande fazenda, o banco, a casa de comércio, a ferrovia, a estrada, o juiz, o cartório, o Estado.
É nessa frente que surge o que em nosso país se chama indevidamente, de pioneiro. São na verdade os pioneiros nas formas sociais e econômicas de exploração e dominação vinculadas às classes dominantes e ao Estado. Essa frente pioneira é essencialmente expropriatória porque está socialmente organizada com base numa relação fundamental, embora não exclusiva, que é a de compradores e vendedores de força de trabalho (MARTINS, 1982, p. 75, grifo do autor).

Com isso, a "frente de expansão", que analogicamente é o movimento demográfico de formação do "sertão" ou fronteira de Turner, é para Martins (1982) o movimento de formação da "fronteira demográfica". Isso, enquanto que a "frente pioneira" é o movimento civilizador do espaço com a implantação dos aspectos econômicos, culturais e sociais, formando a "fronteira econômica".

Quando se dá a superposição da frente pioneira sobre a frente de expansão, surgem os conflitos pela terra. Embora essa distinção tenha um forte peso analítico, ela nos ajuda a entender e a caracterizar as áreas de tensão social, a definir os seus personagens, a natureza de seus conflitos: a posse, de um lado, e a propriedade privada, mais especificamente a propriedade capitalista, de outro. [...]. (MARTINS, 1982, p. 75). 
Nota-se, então, que a frente pioneira exprime um movimento social cujo resultado imediato é a incorporação de novas regiões pela economia de mercado. Ela se apresenta como fronteira econômica. Compreendê-la como tal, no entanto, implica considerar que, no caso brasileiro, a fronteira econômica não coincide com a fronteira demográfica. "A faixa entre uma e outra, embora sendo povoada, não constitui basicamente uma frente pioneira e não constitui basicamente porque sua vida não está estruturada primordialmente a partir de relações com o mercado" (MARTINS, 1975, p. $45)$.

Para Martins (1982, p. 86) a dinâmica da fronteira se processa da seguinte forma: 1) deslocamento de contingente populacional expropriado para a região; 2) expulsão de lavradores e trabalhadores rurais do local e 3) territorialização da grande empresa capitalista. Quase sempre, ao final dessas fases com a consolidação da fronteira, a estrutura fundiária se apresentará concentrada.

Depreende-se que a expansão demográfica ocorre vinculada a fatores econômicos gerados no âmbito da fronteira que tende a se expandir. Sendo assim, a fronteira demográfica aparece, primeiro, movida pelas "gentes" marginalizadas do processo econômico que deixa de ser novidade, gerador de oportunidades. Por isso, retoma-se o movimento para novos espaços através da frente de expansão.

A frente de expansão se integra com a economia de mercado de dois modos: pela absorção do excedente demográfico que não pode ser contido em espaços econômicos já integrados e pela produção de excedentes que se realizam como mercadorias na economia de mercado. Desse modo, a frente de expansão está integrada na formação capitalista (MARTINS, 1975, p. 46), mas ainda não é a implantação da lógica capitalista totalmente territorializada no lugar, ou seja, não é a frente pioneira.

Assim, os conceitos de Martins (1982) parecem ser os mais apropriados para explicar os fenômenos demográficos e econômicos na formação do espaço acriano, por isso, serão tomados como referencial neste trabalho. Portanto, "frente de expansão" é o movimento demográfico de formação espontâneo e a "frente pioneira" é o movimento do capital na formação que se institucionaliza. Ambos os movimentos comportam a lógica totalizante da fronteira em temporalidade diversa que se localizam num espaço. 
Nesse sentido, compreender as dinâmicas ocasionadas destas frentes, como componentes formadores da fronteira, é um caminho para entender o avanço do capitalismo e dos conflitos e problemas gerados na Amazônia acriana.

\section{A frente pioneira extrativa e o primeiro momento da fronteira econômica: a origem das desigualdades}

A inserção do Acre na fronteira brasileira no século XIX se fez, inicialmente, pela introdução da região na divisão internacional do trabalho e da produção. Esta inserção se deu inicialmente com a formação de uma área fornecedora de matéria-prima para a indústria em centros desenvolvidos da Europa e EUA.

Cabia ao lugar, que se tornaria o território acriano, fornecer a borracha extraída da floresta nativa à custa do deslocamento da "mão de obra" assalariada brasileira, vinda do nordeste e respondendo à dinâmica do capital industrial. Cabe enfatizar que o Acre não era ainda Brasil, nem Bolívia ou Peru, mas se inseria no âmbito limítrofe da perspectiva expansionista do país, perante a lógica de resposta à inserção brasileira no circuito do capitalismo mundial. Nessa conjuntura, a condição de ser fronteira sobressai. Mas, trazendo sempre no seu interior estas outras características que deram conteúdo a questão agrária regional, na maior parte do século XX.

A expansão capitalista, com o empreendimento extrativista e suas instituições, sobrepôs diretamente à formação da população nativa. Como o movimento populacional para esta região não foi espontâneo nem, tampouco, movido por agricultores "camponeses" expropriados de outras regiões, não há, portanto, uma frente de expansão como tratado anteriormente. Há sim, uma frente pioneira que se impõe diretamente sobre territórios indígenas.

No contexto da conjuntura econômica mundial, este ato baseou-se na exportação de capitais, fortemente influenciada pela mudança da livre concorrência para o capitalismo monopolista mundial. Isso, ao mesmo tempo em que se buscava encontrar novos espaços no campo do investimento através da exportação de bens, na tentativa de impedir a 
queda da taxa de lucro, no circuito da movimentação do capital industrial no mundo.

A frente pioneira extrativista vinculou-se ao circuito econômico industrial internacional do fim do século XIX, caracterizando-se pelo expansionismo no "desbravamento" da região. Como consequência, proporcionou a formação demográfica do território acriano por forças de pessoas que se deslocaram para o extremo Oeste do Brasil na condição de mão de obra para o trabalho extrativo. Isso se apresenta como expressão da mobilidade da força de trabalho em resposta à mobilidade de capital, que ocorria no interior do Continente Sulamericano. Tais mudanças inseridas na fronteira terão reflexos nas dinâmicas populacionais e espaciais.

Como a economia da borracha era baseada na extração da hévea brasiliensis nos seringais nativos da Amazônia, na sua forma extensiva, a primeira implicação na questão agrária regional é a concentração da propriedade da terra. Isso, considerando a forma de reprodução do sistema seringal em grandes extensões de terra que, em síntese, era um latifúndio e estaria ligada ao seringalista - uma forma de latifundiário ${ }^{3}$. Com isso, no início da ocupação territorial, a terra já se encontrava monopolizada/concentrada e isso acarretou a base fundamental para a exploração do trabalho e, como consequência, para a concentração de renda.

A economia da borracha atingiu o auge em 1912, com uma produção de 42.410 toneladas. No entanto, no ano de 1913, a produção de borracha nativa entrou em decadência após a quebra do monopólio brasileiro no mercado mundial, com a concorrência da produção de outras regiões mundiais.

Influenciada pela diminuição da extração, graças à concorrência da borracha asiática, a produção amazônica chegou ao fracasso quase total em

${ }^{3}$ [...] A grande propriedade era o tipo dominante, caracterizando o que hoje chamamos de "latifúndio"; porém, aqui também cabe ressalva: os seringais tinham em geral, tamanhos relativamente grandes, mas na fase áurea da borracha constituía-se em propriedades produtivas (para os padrões exigidos). Portanto, nesta fase se assim caracterizarmos, devese considerá-los latifúndios por "dimensões"; estas propriedades tornam-se improdutivas com a gradativa decadência da economia extrativista da borracha ao longo do século XX (SILVA, 2003, p. 91). 
1930 com uma produção de 17.131 toneladas de borracha, contra 800.808 toneladas de borrachas asiáticas.

Durante a Segunda Guerra Mundial, ocorreram novas tentativas de retomada da produção; no entanto, seus benefícios duraram apenas poucos anos. Foram influenciados pelos Acordos de Washington, só que , desta vez, o ciclo da borracha durou menos tempo. Foi, na verdade, uma "estratégia econômica de guerra", tendo o seu auge de 1942 a 1945; a partir de então, veio mais uma vez a estagnação e a decadência. Mesmo assim, muitos seringueiros permaneceram nos seringais até chegar à década de 1980. Nesse momento, praticamente se extingue a economia da borracha na região e se inicia a nova fase da/na fronteira.

Esta nova fase da/na fronteira acriana firma-se com o grau de decadência da produção de borracha e de seu mercado e com a implantação e fortalecimento de práticas agropecuárias. Os seringalistas vendem as vastas áreas para os pecuaristas que se voltam ao uso do solo na formação de pastagens. Assim, parte da floresta vai sendo derrubada, embora ela continuasse sendo habitada pelos seringueiros. Por isso, há a luta dos seringueiros pela floresta enquanto seu território de vivência. Tal situação passa a ser uma barreira contra o desenvolvimento das forças produtivas centro-sulistas que começavam a se territorializar, em meados da década de 70 do século XX.

\section{A frente pioneira agropecuária: o conflito pela terra e trabalho}

Por volta da década de 70 do século $\mathrm{XX}$, aconteceu a rearticulação do capital no território acriano, transformando a sociedade, a economia e a política. Foi a caminhada da frente pioneira agropecuária e a formação da nova fase da fronteira econômica no estado.

A fronteira agropecuária, mais recente, configura-se numa frente pioneira que "propõem" novas formas e condições de trabalho e produção, readequando-se aos novos momentos do capitalismo na sua territorialização em nível nacional. Impôs transformações tanto no caráter de produção, como sociocultural e socioeconômico. Por "propor" novas formas de produção e trabalho, numa visão do "novo" quebra como o arranjo espacial da fase extrativista, no campo e na cidade. 
Nisto reside às raízes e abrangência dos conflitos produzidos (SILVA, 2004, p. 43).

A compra das terras dos seringais acrianos por empresários do Centro-Sul do país, no início da década de 1970, instaurou um mundo de violência nos seringais. Isso porque a inserção da agropecuária na floresta discordava com a matriz de uso do solo para o extrativismo, forçando a finalização do sistema tradicional da economia extrativa em bases florestais.

A abertura mercadológica da terra gera outro problema: o conflito com as famílias de seringueiros que já viviam como posseiro no interior dos seringais. Eles não seriam diretamente remanejados para outra atividade nem, tampouco, absorvidos em sua maioria pela agropecuária. Dessa forma, o novo dono da terra se incumbiria de "limpá-la" dos resquícios do seringal. Essas limpezas aconteceram por duas formas: via indenização ou por uso da violência ${ }^{4}$. Ambos geraram a expropriação de muitas famílias.

A mudança territorial do seringal (floresta) para a agropecuária (fazenda) se processava em três fases: 1) A "limpeza" da floresta; 2) A "limpeza" da mão de obra extrativista (posseiro) e; 3) O plantio do capim.

Esse processo de desfazer a velha territorialização do seringal, para uma nova territorialização da fazenda, desencadeou uma série de ações violentas contra os seringueiros remanescentes. "Desimpedir a área da presença incômoda de seringueiros e pequenos posseiros passou a ser uma operação prioritária” (SILVA, 1982, p. 32).

Os seringueiros, temendo o fim do seu modo de vida com o fim dos seringais, passaram a se articular em movimentos sociais. A partir de 1975 começaram a surgir os primeiros Sindicatos dos Trabalhadores Rurais STR's. Na década seguinte, outras organizações surgiram, como é o caso do Conselho Nacional dos Seringueiros - CNS. Nessa época, surge Chico Mendes, o principal protetor do modo de vida seringueiro, que se fazia em

${ }^{4}$ Os métodos de expulsão utilizados contra os posseiros foram os mais diversos, desde a compra da posse e benfeitorias por preços irrisórios ou troca por lotes, de área inferior ao módulo oficial, à destruição de plantações, invasão de posses, proibição de desmate para roçados, obstrução de caminhos e varadouros, espancamentos e assassinatos. 
harmonia com a floresta. Foi justamente no seio da resistência criada por essa liderança na cidade de Xapuri com as estratégias dos tão poderosos "empates" "que se gestou o que seria no futuro a esperança dos seringueiros: as Reservas Extrativistas - RESEX, que foi uma forma de Reforma Agrária seringueira (PAULA, 2006, p. 118).

[...] A liderança de Chico Mendes conseguiu projetar a luta
dos seringueiros para muito além dos limites políticos
nacionais e de seus significados sociais. A sua morte fora uma
tentativa de silenciar o movimento, atingindo a maior
expressão das lideranças, inclusive reconhecida
internacionalmente. Na verdade o impacto negativo na
opinião pública mundial forçou ações imediatas como o
reconhecimento das RESEX's, a prisão dos assassinos e a
viabilização de vários projetos que poderiam ter promovido
melhorias efetivas na vida dos camponeses florestais,
sobretudo, acreanos ou, ao menos, xapurienses (SILVA,
2006, 167).

Não bastassem os problemas acarretados no espaço agrário acriano que provocou, entre outras coisas, a forte mobilidade da população, os reflexos da frente pioneira agropecuária se transmutaram para as questões urbanas na capital acriana, como consequência do forte êxodo rural e dos muitos conflitos. Na cidade de Rio Branco, o assassinato do líder sindical João Eduardo, em 1981, demonstrou que os conflitos agrários se refletiam também nas questões da terra para moradia urbana.

Nas últimas décadas do século XX, a principal forma de ampliação e surgimento de novos bairros em Rio Branco era por meio de ocupações populares, resultado da luta pela terra de moradia. Assim, a população do município de Rio Branco que, até a década de 1970, era predominante rural (SILVA, 2003), na década de 1980 passa ser predominantemente urbana.

Em suma, pode-se dizer que as duas primeiras fases da fronteira econômica acriana (extrativismo e da agropecuária) produziram espaços econômicos e de desenvolvimentos para o capital, mas também, conflitos e

${ }^{5}$ Empate vem de empatar, ou seja, uma forma de resistência dos seringueiros contra o usurpador do seu território, os "paulistas", ou seja, a oposição do seringueiro contra o fazendeiro (PAULA, 2006, p. 112). 
desigualdades sociais e territoriais. Dados considerando que estes pontos da caracterização agrária acriana permanecem, chegamos agora em condições de pensar sobre qual é a face da fronteira econômica atual no Acre. Como se coloca esta fronteira perante as novas fases do ambientalismo e do agronegócio?

\section{O agronegócio florestal e a consolidação da frente pioneira agropecuária no século XXI}

Vimos que a expansão dessa fase foi inicialmente marcada pela entrada da agropecuária, no entanto, apenas na última década do século XX. E, já na primeira década do século XXI, as lavouras mecanizadas começaram ser ampliadas. Com isto, há um revigoramento da fronteira econômica, sem mobilidade externa de população.

Tem-se o redirecionamento na lógica produtiva sob a ótica de operacionalização pelo capitalismo, perante a ampliação para o agronegócio: por um lado, a ação modernizadora da agropecuária e, por outro, o aprofundamentos de viés ecológico/ambiental. Esta expansão vem com o objetivo de integrar o Acre ao sistema produtivo nacional, voltado para a produção de commodities. Esse processo baseia-se em modelos que ligam a agricultura com a indústria, criando um sistema de produção altamente competitivo.

Constitui, então, como uma nova fase na fronteira, sob a lógica de uma possível "frente técnico-ecológica". Aqui o produto ainda é agropecuário (gado, milho, cana de açúcar) e agroflorestal (madeira). Mas a grande mudança está no sentido da mercadoria aí circulada. A mercantilização se faz de modo mais forte pela impregnação de caráter fictício da mercadoria como "produto verde". Este surge como um fetiche que responde ao momento histórico de ser ecologicamente correto e sustentavelmente viável do ponto de vista econômico. Portanto, é uma fase em que a fronteira está marcada pelo agronegócio, vinculando a expansão do "capitalismo verde" sobre territórios florestais. Neste mercado, tudo é verde: "boi verde", "álcool verde", "borracha verde", entre outros. Por isso, pode-se falar de uma expansão agrícola/agropecuária/agroextrativista, sob "ecologização" da produção, como aquilo que seguramente podemos tratar como faces do "agronegócio verde" na Amazônia. 
Para exemplificarmos vamos, sucintamente, tratar apenas de dois produtos que mais incorporam esta fase vivida pelo agrário acriano: a canade-açúcar e a madeira. Nessa perspectiva, a expansão do agronegócio da cana-de-açúcar em curso, no caso do Acre, pretende servir de paradigma de desenvolvimento para dinamizar as atividades agropecuárias no estado. Cabe ressaltar que essa expansão é viabilizada com forte apoio estatal. De forma similar com o que ocorreu na formação da fronteira agropecuária nos anos 70 do século XX, o governo estadual faz propaganda, promove isenção fiscal e fornece a infraestrutura básica necessária para atrair empresários de todo o Brasil a investirem no Acre, no início do século XXI.

De forma geral, como expressão disso, nos dados abaixo, podemos observar um cenário da territorialização do setor sucroalcooleiro na região nos últimos anos:

[...] Aumento na produção de cana na Amazônia de 17,6 milhões para 19,3 milhões entre 2007 e 2008 . No Tocantins, a expansão será de $13 \%$ (de 4,5 mil para 5,1 mil hectares), seguido do Mato Grosso, com aumento de $10 \%$, e do Amazonas, com 8\% (de 4,8 mil para 5,2 mil hectares). No Pará, a área plantada deve ficar em torno de 10,5 mil hectares. Segundo pesquisa da Universidade de São Paulo (USP), o Pará é visto como uma das principais áreas de expansão para produção de etanol (REDE, 2008, p. 21).

No Acre, baseado também nessa lógica expansiva e produtiva do "agronegócio verde" foi formada a Agroindústria Álcool Verde ${ }^{6}$. Tais investimentos surgem, tendo em vista que o governo do estado do Acre, aproveitando-se da conjuntura em que se encontravam os biocumbustíveis no governo do presidente Lula com a retomada do etanol como combustível, adquiriu junto ao Banco do Brasil a área de 61,572 hectares,

6 No âmbito agropecuário e extrativista, ainda temos de considerar que há produção de outras mercadorias que marcam estas faces do agronegócio atual acriano, todos incentivados pelo Estado: a agroindústria de processamento de frango (ACREAVES), o Complexo Agroindustrial para produção de açúcar e álcool (Álcool Verde), a indústria de Tacos de Madeira, fábricas de farinha de mandioca, beneficiamento de castanha-do-Brasil, a Indústria de Camisinha e o Pólo Florestal de Xapuri. 
por R \$ 2,7 milhões. Esta base física era o que restara do maquinário da antiga Usina Álcool Brasileiro S.A - ALCOBRÁS (projeto de décadas anteriores, que estava desativado), que os repassou para a iniciativa privada gerir, por meio de grupos tradicionais neste ramo da agroindústria, pelo prazo de vinte anos.

A reestruturação produtiva provocada pelo avanço do agronegócio da cana-de-açúcar pode ser constatada no local pela inserção cada vez maior de áreas de assentamentos rurais como o PA Alcobrás e PA Zaqueu Machado, para fins de arrendamento para o plantio da cana-de-açúcar. Com isso, a condição de produtor de alimentos básicos perde lugar, com aparentes reflexos nas condições de vida das famílias locais. Isto, no conjunto com as mudanças do que se produz e das relações de trabalho, marca nova forma com que o capitalismo se territorializa na região (em especial no eixo de influência da Rodovia BR-317), suprimindo o espaço da produção familiar.

A feição espacial do agronegócio florestal está voltada para o uso dos recursos florestais, sobretudo madeireiro. Então, sob a lógica do uso sustentável, as práticas em que se tem o manejo florestal marcam um processo que inicia na mata e finaliza no circuito de venda do produto, sob a certificação. $\mathrm{Na}$ verdade, há um forte apelo para o sentido ecológico da madeira manejada, muito embora sua exploração seja feita amparada em um cabedal jurídico ${ }^{7}$ que legitima, de forma verdadeira, a lapidação dos recursos florestais.

Em suma, o agronegócio florestal tem surgido como mecanismo de resolução de um problema que está na raiz de uma zona de fronteira: aqui se tem oferecido novas possibilidades de exploração para o capital na sua apropriação da floresta, sem assumir a responsabilidade pelos impactos/danos causados. Eles ficam com as comunidades envolvidas no manejo ou com o próprio Estado, quando a área concedida é unidade de conservação (UC). Normalmente, os problemas, segundo as autoridades,

${ }^{7}$ A Lei 11284/06 expressa de forma lapidar o modo com se processa a retomada do território pelo capital. Ao legislar sobre a extração da madeira, abre grande possibilidade de conflitos com as forças empresariais. Isso, dado que a participação da população tradicional da floresta é, em muitas vezes, restrita, sobretudo nos ganhos obtidos. Embora, ao que parece, estes ainda não tomaram consciência da magnitude do processo mais amplo que envolve a reprodução da sociedade em sua totalidade. 
podem ser resolvidos a partir de um aporte técnico, ecologicamente correto e economicamente viável - por isso, falarmos de uma possível fronteira guiada pelo vetor técnico-ecológico.

Não se pode falar deste vetor técnico-ecológico como uma nova frente pioneira consolidada ou mesmo a consolidar. A nosso ver, trata ser uma fase de amadurecimento dos períodos anteriores, quando se implantou a base da produção capitalista desse espaço. Agora, as relações capitalistas norteadas pelo paradigma ecológico, promovem um rearranjo territorial, recriando espaço para o agronegócio, incorporando os setores produtivos rurais (agricultura, agropecuária e agroextrativismo) sob a lógica do "esverdeamento" da mercadoria, mesmo que à custa da segregação ainda maior da população rural.

Portanto, mesmo no contexto das incipientes transformações que ocorreram na dinâmica da fronteira, as mudanças nas bases estruturais da distribuição da terra foram poucas. Assim, a concentração da terra foi e continua sendo uma das marcas da questão agrária, como o restante do Brasil.

Nessa questão em si e nos seus conflitos decorrentes, situam-se bases fundamentais da questão agrária acriana. Estas dinâmicas capitalistas produziram problemas, tais como: criação e manutenção de uma estrutura fundiária concentrada, a degradação da floresta nativa, a violência contra os posseiros, a exploração da força de trabalho, o desemprego rural e urbano e a luta por moradia na cidade, entre outros. Desses fatos, trataremos a seguir.

\section{A estrutura fundiária acriana e a expressão das desigualdades}

Como vimos, as duas frentes pioneiras expostas anteriormente: a consolidação da grande propriedade e a forte exploração do trabalhador, foram as maiores implicações na questão agrária. Essa herança é evidente na estrutura fundiária do Acre.

Segundo informações cadastrais do INCRA (2004), os imóveis com áreas acima de 1.000 hectares (grandes) concentravam cerca de 78,77\% da área cadastrada e constituem, apenas, 3,44\% da quantidade de imóveis. Os imóveis com áreas entre 100 a 1.000 hectares (médios) correspondem a $7,87 \%$ e concentravam $6,06 \%$ da área cadastrada, enquanto os 
estabelecimentos com até 100 hectares (pequenos) representam 88,69\% do total cadastrado e mantinham apenas $15,17 \%$ da área cadastrada (MDA, 2004, p. 27).

Esses dados demonstram uma prevalência da minoria dos grandes imóveis $(3,44 \%$ do total), concentrando a propriedade da terra no estado. Uma causa para esta evidência é atribuída ao modelo incentivado durante a expansão da fronteira agropecuária da década de 70 do século XX, baseado na grande exploração. Em contrapartida, para a grande maioria $(88,69 \%$ do total) dos pequenos imóveis ou camponeses (até 100 ha), que vivem no/do restam, apenas $15,17 \%$ da área conforme a Tabela 01 .

Tabela 01 - Estrutura Fundiária do Acre, 1999.

\begin{tabular}{l|c|c}
\hline \multicolumn{1}{c|}{ Estratos área total (ha) } & \% dos imóveis & \% de área \\
\hline Até 100 & 88,69 & 15,17 \\
\hline De 100 a 1.000 & 7,87 & 6,06 \\
\hline Acima de 1.000 & 3,44 & 78,77 \\
\hline Total & $\mathbf{1 0 0}$ & $\mathbf{1 0 0}$ \\
\hline
\end{tabular}

Fonte: INCRA, 2004. Organizado por Cleilton Sampaio de Farias, 2012.

Para entender melhor esta questão, no caso do Acre, o índice de Gini $^{8}$ do ano de 2003 era de 0,785 , o que colocava o estado em terceiro lugar entre aqueles de maior concentração fundiária da Amazônia (GIRARD, 2006). Esse valor, se analisado juntamente com os dados dos anos de 1966 a 2003, pode demonstrar uma pequena redução no nível de concentração da estrutura fundiária, muito embora, ainda permaneça bem concentrado.

${ }^{8}$ Nos estudos da estrutura fundiária,o índice de Gini é uma das formas mais usadas para visualizar a situação em que se encontra a estrutura. Para o seu cálculo, utiliza-se como unidade básica o proprietário e a área total que detém e o seu valor varia de 0 a 1 , de acordo com o nível de concentração: quanto mais se aproxima de 0 , o índice indica igualdade; no entanto, quando se aproxima de 1, indica concentração absoluta. Segundo Girard (2006), "em 2003, o índice de Gini para o Brasil era 0,816, o que indica grande concentração, já que quanto mais próximo de um maior é o grau de concentração da terra". 
Entre os anos de 1966 e 1984 - período inicial da expansão da fronteira agropecuária - percebemos um aumento gradual no índice. $\mathrm{O}$ índice estadual era de 0,948 em 1966; no ano de 1978, ocorreu um acréscimo de 0,013 passando para 0,961 e baixando para 0,919, em 1984. Percebe-se que o índice chega perto de 01 , que seria a concentração total.

De 1984 a 1998 o índice sofre diminuição de 0,04 , chegando a 0,879 e de 1998 a 2003, sofre a maior subtração que é de 0,094, chegando ao menor índice calculado até então, 0,785 (MDA, 2004, p. 26). O Gráfico 01apresenta a evolução do índice de Gini, no estado.

Gráfico 01 - Evolução do índice de Gini - Estado do Acre (1966 - 2003).

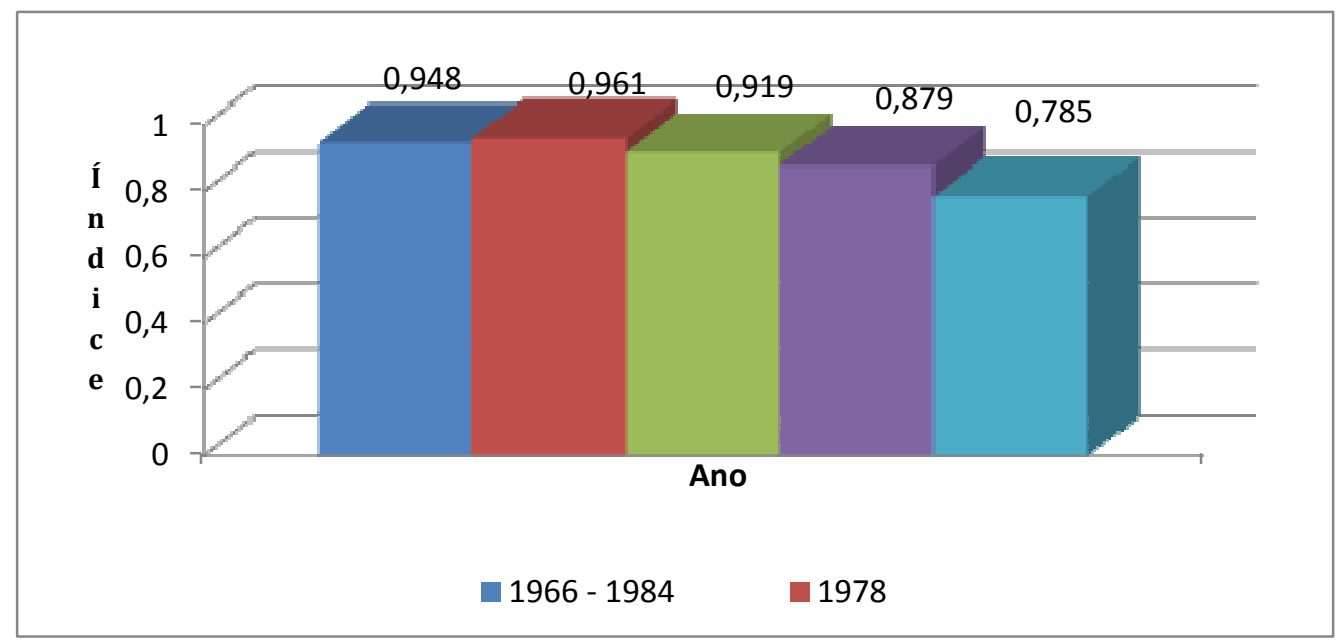

Fonte: ZEE/AC e INCRA nos anos de 1966-1984, 1978, 1984 e 1998 e, Girard (2006) para o ano de 2003. Organizado por Cleilton Sampaio de Farias, 2012.

Entre os fatos que justificam tal diminuição, há dois pontos processuais vistos nas últimas décadas do século passado: a mudança da matriz produtiva extrativa para a pecuária e a incipiente política de colonização e Reforma Agrária por meio de assentamentos. Os assentamentos ampliam a quantidade de unidade de produção familiar no 
estado, muito embora sobre eles já atuem fortes processo de reconcentração fundiária (MDA, 2004, p. 26).

Em relação ao índice de Gini dos vinte e dois municípios acriano, tinha-se em 1992 o município de Feijó com o índice de 0,964 - índice bem próximo do 1 -, sendo o mais concentrado e o município de Plácido de Castro com 0,337, como o menos concentrado, conforme tabela 02 .

Tabela 02 - Índice de Gini dos municípios do Acre - 1992, 1998 e 2003

\begin{tabular}{l|c|c|c|c}
\hline \multicolumn{1}{c|}{ MUNICÍPIO } & REGIONAL & $\mathbf{1 9 9 2}$ & $\mathbf{1 9 9 8}$ & $\mathbf{2 0 0 3}$ \\
\hline Assis Brasil & Alto Acre & 0,651 & 0,655 & 0,683 \\
\hline Brasiléia & Alto Acre & 0,571 & 0,512 & 0,713 \\
\hline Epitaciolândia & Alto Acre & $\mathrm{X}$ & 0,819 & 0,838 \\
\hline Xapuri & Alto Acre & 0,844 & 0,862 & 0,833 \\
\hline Acrelândia & Baixo Acre & $\mathrm{X}$ & 0,254 & 0,447 \\
\hline Bujari & Baixo Acre & $\mathrm{X}$ & 0,880 & 0,882 \\
\hline Capixaba & Baixo Acre & $\mathrm{X}$ & 0,824 & 0,799 \\
\hline Plácido de Castro & Baixo Acre & 0,337 & 0,507 & 0,402 \\
\hline Porto Acre & Baixo Acre & 0,665 & 0,767 & 0,713 \\
\hline Rio Branco & Baixo Acre & 0,840 & 0,836 & 0,801 \\
\hline Senador Guiomard & Baixo Acre & 0,396 & 0,448 & 0,479 \\
\hline Manoel Urbano & Purus & 0,910 & 0,894 & 0,849 \\
\hline Sena Madureira & Purus & 0,933 & 0,929 & 0,833 \\
\hline Santa Rosa do Purus & Purus & $\mathrm{X}$ & $\mathrm{X}$ & $\mathrm{X}$ \\
\hline Feijó & Tarauacá/Envira & 0,964 & 0,958 & 0,877 \\
\hline Jordão & Tarauacá/Envira & 0,650 & 0,758 & 0,779 \\
\hline Tarauacá & Tarauacá/Envira & 0,930 & 0,921 & 0,837 \\
\hline Cruzeiro do Sul & Juruá & 0,465 & 0,383 & 0,652 \\
\hline & & & & \\
\hline
\end{tabular}




\begin{tabular}{l|c|c|c|c}
\hline Porto Walter & Juruá & 0,659 & 0,725 & 0,886 \\
\hline Mâncio Lima & Juruá & 0,533 & 0,851 & 0,911 \\
\hline Mal. Thaumaturgo & Juruá & $\mathrm{X}$ & 0,625 & 0,813 \\
\hline Rodrigues Alves & Juruá & $\mathrm{X}$ & 0,527 & 0,635 \\
\hline
\end{tabular}

Fonte: Girard (2006).

No ano de 1998, a maior concentração fundiária ainda era o município de Feijó com o índice de 0,958. Isto significava apenas 0,08 a menos que o ano de 1992. Já o município de menor concentração era o de Acrelândia com 0,254 de índice.

Assim, os dados apresentados indicam que em relação à estrutura fundiária do estado, ocorreu uma significativa diminuição quando se toma como ponto de partida o índice de Gini dos anos de 1966 a 2003, de 0,948 para 0,785 .

Este fato pode ser confirmado quando se analisa a quantidade de estabelecimento e a área ocupada. Percebe-se que poucos imóveis $(3,44 \%$ $=78,77 \%$ ) concentram a maior parte das terras disponíveis. Enquanto isto, muitos imóveis $(88,69 \%=15,17 \%)$ dividem uma pequena parte. Acrescenta-se que a maior parte dos trabalhadores está ocupando esta pequena parte, ou seja, $72 \%$ deste total.

Analisando esses dados em conjunto com aqueles da estrutura fundiária do estado, percebe-se que a agricultura capitalista concentra a maior parte das terras. No entanto, é a agricultura familiar que, com pequena quantidade de terra disponível, ocupa a maior parte dos trabalhadores rurais ${ }^{9}$. Isso indica que a agricultura capitalista se beneficia

${ }^{9}$ Ressalto aqui que há muitos estudiosos que questionam esta ótica da distinção que aqui fazemos entre capitalista e não capitalista. Nós estamos trabalhando com a tese da Reprodução ampliada e contraditório do capital (MARTINS, 1983; OLIVEIRA, 1990). Portanto, as empresas rurais são instância do capitalismo, mas a unidade de produção familiar, diretamente não é (é uma forma de reprodução econômica não capitalista). Nela, o capital exerce influência direta, apenas pelos processos de circulação de mercadorias; o valor produção nem sempre é repassado ao valor mercadoria do produto. Sendo assim, a 
com as grandes extensões fundiárias, mas não dispõe de força de trabalho para sua exploração. Por outro lado, a produção familiar concentra maior número de pessoas em poucas terras. Nesta unidade de produção vivem muitos trabalhadores, formando a maior parte dos moradores do campo, conforme Gráfico 02.

Gráfico 02 - Pessoal Ocupado nas Atividades Rurais por setor - Acre.

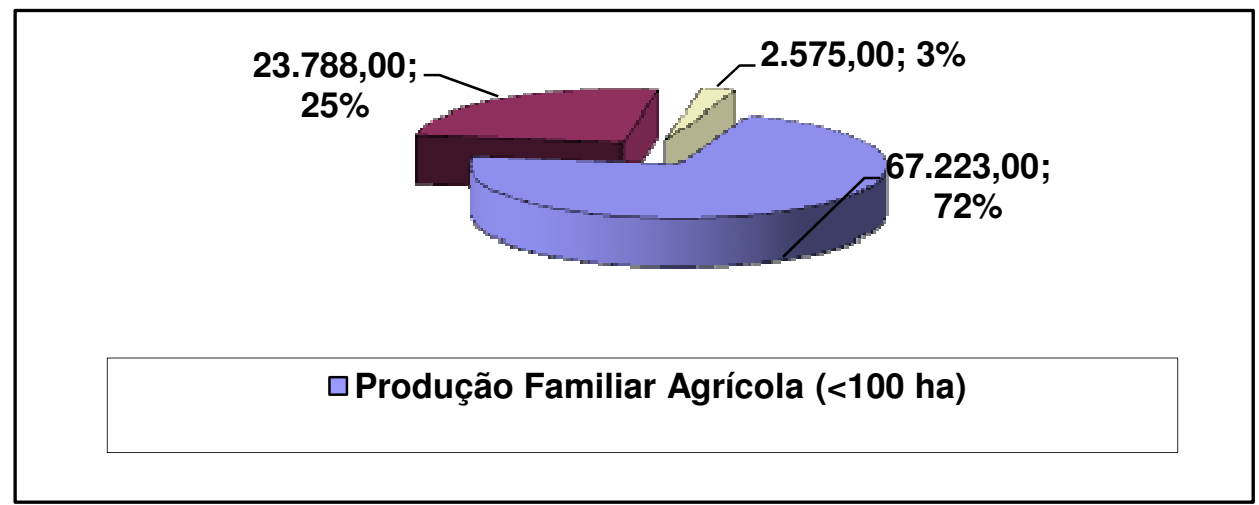

Fonte: MDA (2004, p.43). Organizado Por Cleilton Sampaio de Farias, 2012.

Em suma, pode-se dizer que a questão agrária do estado na dimensão espacial é a própria representação do movimento que a gerou, a fronteira econômica com a frente pioneira extrativa e a frente pioneira agropecuária. Entre as implicações que o capital gerou e ampliou estão a concentração fundiária e a expropriação e a exploração dos trabalhadores.

unidade familiar subordina-se à lógica macro do capital, mas não é unidade capitalista, pois pode operar sob lógicas que responde às suas necessidades em primeira mão e não às lógicas do mercado. A unidade de produção familiar poderá tornar-se uma empresa rural capitalista, mas não é a regra dominante; em geral, produzem sob lógica não capitalista, embora venda seus produtos para completar o suprimento de suas necessidades na aquisição daquilo que não produz em sua unidade de produção. É "neste sentido que tratamos de empresas capitalistas" e "unidade de produção familiar". 
Complementando, a isso incide a exclusão, a violência e toda forma de desigualdade que dessa dinâmica procede.

\section{Considerações finais}

A dimensão da questão agrária acriana, ainda, poderia ser dada com ênfase em outros pontos pouco ou não mencionados até aqui como, por exemplo, a questão da legalização da propriedade fundiária e as formas de assentamentos rurais (agrícolas e extrativistas).

Contudo, optamos por abordar a partir da questão da fronteira, por entender que, desde o princípio de sua ocupação até os dias atuais, o Acre tem sido visto e produzido como local de novas possibilidades de articulação do capitalismo. Assim, o Acre surgiu enquanto território nacional como fronteira política; hoje, porém, ainda se coloca como zona limítrofe no campo das possibilidades de reprodução socioespacial do capital - isto é, vemo-lo ainda como uma fronteira econômica.

Como uma sociedade que se forma, a fronteira é lócus de conflitos, confrontos à luz do processo impostos na sua reprodução. Então, mesmo já tendo larga expressão urbana de sua população, as lógicas produtivas acrianas provêm de suas maiores potencialidades que se encontra, no ambiente agrário. Com isso, a questão da fronteira para o Acre, ainda se coloca como parte fundamental de sua inserção no âmbito das questões agrárias nacionais e internacionais, sobretudo pela inserção territorial como espaço para a expansão do agronegócio. Isto, por exemplo, pode ser notado no tocante à exploração madeireira e à ampliação do rebanho bovino, atividades que nos últimos doze anos vêm crescendo fortemente.

A fronteira atual reflete as contradições das forças que produziram suas fases anteriores, seja com a frente extrativista inicial ou com a frente agropecuária, já pós 1970. Muitos processos sociais e econômicos atuais buscam resgatar bases constituídas nas lutas dos seringueiros, personificados na figura importante de seu principal líder Chico Mendes, colocando isso como justificativa para os avanços do capitalismo verde. Tudo isto vem conjugado a fluxos de inovaçõ̃es, fundadas em amplas informações técnico-científicas modernas na constituição ideológica de bases "ecologicamente corretas" de exploração de recursos naturais das florestas. 
Isso, de modo geral, traz para debate um forte conteúdo ideológico da questão agrária. Sendo que sob a luz do "esverdeamento" da produção rural, na atualidade, se redimensiona o uso do espaço, muitas vezes, negando totalmente os ideais de lutas dos seringueiros, liderados por Chico Mendes. Mas com isto, justifica-se uma base para a propagação do modelo de Desenvolvimento Sustentável do espaço amazônico, embora mantendo a mesma estrutura expropriatória dos grupos sociais e depredadora da natureza.

$\mathrm{Na}$ atualidade, isso faz com que o Acre (como outras partes da Amazônia) possa ser inserido no conjunto da reprodução capitalista nacional como área com potenciais naturais, ainda a ser explorada, isto é, como fronteira econômica apta a novas articulações do capital.

\section{NA FRONTEIRA DISTANTE: UM ENSAIO SOBRE A QUESTÃO AGRÁRIA ACRIANA À LUZ DE SUA FORMAÇÃO ECONÔMICA E SOCIAL}

Resumo: Este artigo aborda, a partir da dinâmica da "fronteira", a formação da questão agrária acriana. Isso por entender, através da relação dialética, que desde o princípio da ocupação do território acriano até os dias atuais, a fronteira tem sido vista como local de novas possibilidades de articulação do capital. Sendo assim, desenvolve-se, na primeira parte, uma análise sobre frente/fronteira e as suas representações no espaço acriano e, na segunda parte, as implicações das frentes/fronteiras na questão agrária local com a análise da estrutura fundiária. Em vista de tudo isso, a fronteira demográfico-econômica proporcionou as situações de maiores contradições na produção do espaço rural acriano, que, nesse caso, são marcadas na história e perpetuadas no espaço agrário, através da estrutura fundiária concentrada e de seus desdobramentos na concentração de renda e exploração do trabalhador.

Palavras - chave: frente, fronteira, questão agrária, estrutura fundiária, Acre.

\section{DISTANT FRONTIER: AN ESSAY ON AGRARIAN QUESTION IN ACRE STATE THROUGH ITS ECONOMIC AND SOCIAL FORMATION}

Abstract: This article discusses, from the dynamics of the "frontier", the formation of the agrarian question acriana. That in mind, through the dialectical relationship, that from the beginning of the occupation of the territory acriano 
until today the frontier, has been seen as a place of new opportunities for joint capital. Thus, develops in the first part of an analysis of front / frontier and their representations in space acriano and in the second part, the implications of fronts / frontier in place with the agrarian question agrarian structure analysis. In view of all the frontier provided the demographic-economic situations of major contradictions in the production of rural acriano, which in this case are marked in history and perpetuated in agrarian space by concentrated land structure and its developments in the concentration of income and exploitation of the worker.

Keywords: front, frontier, agrarian question, land structure, Acre.

\section{BIBLIOGRAFIA}

FREYRE, Gilberto. (1947). Interpretação do Brasil. Aspectos da formação social brasileira como processo de amalgamento de raças e culturas. São Paulo: Livraria José Olympio.

GIRARD, Eduardo Paulon. (2006). Proposição Teórico-Metodológica de uma Cartografia Geográfica Crítica e sua aplicação no desenvolvimento do atlas da questão agrária brasileira. Presidente Prudente: Universidade Estadual Paulista, Faculdade de Ciências e Tecnologia. Tese de Doutorado.

GONÇALVES, Carlos W. Porto. (2001). Amazônia, Amazônias. São Paulo: Contexto, 178p.

HOLANDA, Sérgio Buarque de. (2005) Monções. São Paulo: Brasiliense.

Editora.

. (1973). Raízes do Brasil. Rio de Janeiro: Livraria José Olympio

(1957). Caminhos e fronteiras. São Paulo: Companhia das Letras.

IBGE. Instituto Brasileiro de Geografia e Estatística. (2009). Levantamento Sistemático da Produção Agrícola. Disponível em:<www.ibge.gov.br>.

INCRA. Instituto Nacional de Colonização e Reforma Agrária. (2004). II PNRA: Programa Nacional de Reforma Agrária. Brasília. Disponível em:< www.incra.gov.br>. Acesso em: 14 out. 2010.

KNAUSS, Paulo (Org.). (2004). Oeste Americano: quatro ensaios dos Estados Unidos da America de Frederick Jackson Turner. Niterói: EDUFF. 
MARTINS, José de Sousa. (1975). Frente Pioneira: contribuição para uma caracterização sociológica. In:___ Capitalismo e Tradicionalismo: estudo sobre as contradições da sociedade agrária no Brasil. São Paulo: Pioneira.

Paulo: Hucitec.

(1982). Expropriação e violência: a questão política no campo. São

- (1983). Os camponeses e a política no Brasil: As lutas sociais no campo e seu lugar no processo político. 2. ed. Petropólis: Vozes, 185p.

. (1997) Fronteira: a degradação do outro nos confins do humano. São Paulo: HUCITEC. 213p.

MDA, Ministério do Desenvolvimento Agrário. (2004). Programa de Reforma Agrária para o Desenvolvimento Sustentável do Acre: Plano Regional de Reforma Agrária (2004- 2007). Rio Branco: MDA.

OLIVEIRA, Ariovaldo Umbelino de. (1990). Modo capitalista de produção e agricultura. 3.ed. São Paulo: Ática, 86p.

PAULA, Elder Andrade de. (2005). (Des)envolvimento Insustentável na Amazônia Ocidental: dos missionários do progresso aos mercados da natureza. Rio Branco: EDUFAC.

PAULA, Elder Andrade de. (2006). Movimento sindical e luta pela terra: do romantismo da voz ao pragmatismo do silêncio. In: PAULA, Elder Andrade de, SILVA, Silvio Simione da. (org.) Trajetória da luta camponesa na Amazônia Acreana. Rio Branco: EDUFAC.

RICARDO, Cassiano. (1970). Marcha para o Oeste: a influência da bandeira na formação social e política do Brasil. Rio de Janeiro: José Olympio.

REDE Social de Justiça e Direitos Humanos e Comissão Pastoral da Terra. (2008). Os impactos da produção de cana no Cerrado e Amazônia. Disponível em: < www.social.org.br>.

SILVA, Adalberto Ferreira da. (1982). Raízes da ocupação recente das terras do acre: movimento de capitais, especulação fundiária e disputa pela terra. Belo Horizonte: UFMG.

SILVA, José Graziano da. (1990). O que é questão agrária. 16. ed. São Paulo: Brasiliense, $114 \mathrm{p}$.

SILVA, Silvio Simione da. (2003). Na fronteira agropecuária acreana. Rio Branco: LEUPAG-DEGEO/UFAC. 
. (2004). O espaço agrário acreano nas últimas décadas do século XX. Revista NERA: Presidente Prudente. Ano 7, n. 4, janeiro/julho de 2004. ISSN 1806-6755.

(2006). Tempos de violência, espaços da resistência. In: PAULA, Elder Andrade de, SILVA, Silvio Simione da. (org.) Trajetória da luta camponesa na Amazônia - Acreana. Rio Branco: EDUFAC.

WAIBEL, Léo H. (1955). As zonas Pioneiras do Brasil. RBG: revista brasileira de geografia. Ano 17, n. 04, out/dez.

Data de Submissão: 14/09/2011

Data de Aprovação: 30/01/2013 